\title{
CAPITULO 20
}

\section{ANALISE DA QUALIDADE DO SONO DE ESTUDANTES UNIVERSITÁRIOS DA ÁREA DE CIÊNCIAS DA SAÚDE}

DOI 10.4322/978-65-995353-2-1.c20

\author{
Geísa de Morais Santana ${ }^{1}$, Célio Pereira de Sousa Júnior ${ }^{2}$, Carlos Eduardo da Silva \\ Barbosa $^{3}$, Francisco Mayron de Sousa e Silva ${ }^{4}$, Izadora Ribeiro de Moraes ${ }^{5}$, Jônatas \\ Lucas Marcelino da Silva ${ }^{6}$, Maria Bianca de Sousa Oliveira ${ }^{7}$, Viviane Gomes de Aguiar ${ }^{8}$, \\ Laércio Bruno Ferreira Martins ${ }^{9}$, Antônio Lucas Farias da Silva ${ }^{10}$ \\ ${ }^{1}$ Universidade Estadual do Piauí, (geisasantana97@gmail.com) \\ ${ }^{2}$ Universidade Federal do Pará, (academicocelio@gmail.com) \\ ${ }^{3}$ Universidade do Grande Rio, (cedsbzs@gmail.com) \\ ${ }^{4}$ Faculdade de educação São Francisco, (Mayronfisioterapeuta@gmail.com) \\ ${ }^{5}$ Universidade Federal de Rondonópolis, (izadoraribeirom@outlook.com) \\ ${ }^{6}$ Universidade Federal de Pernambuco, (jonatas.lucas@ufpe.br) \\ ${ }^{7}$ Universidade Estadual do Piauí, (mbianca007@gmail.com) \\ ${ }^{8}$ Universidade Estadual do Piauí, (vivivgaguiar@gmail.com) \\ ${ }^{9}$ Universidade Estadual do Piauí, (laerciom42@gmail.com) \\ ${ }^{10}$ Centro Universitário UniFacid, (lucas1992farias@gmail.com)
}

\section{Resumo}

Objetivo: O trabalho teve como objetivo avaliar e comparar a qualidade do sono em universitários pendulares e não - pendulares dos cursos da área da saúde Método: Trata-se de uma pesquisa prospectiva, observacional, transversal, descritiva e comparativa. $O$ estudo foi desenvolvido em uma Instituição de Ensino Superior do Piauí, a amostra foi constituída por 28 estudantes pendulares e não - pendulares de estudantes da área da saúde. Foram aplicados o questionário de "Índice de Qualidade do Sono de Pittsburgh" e uma ficha de informações dos participantes elaborada pelas pesquisadoras. Resultados: Destes participantes 78,6\% eram do sexo feminino e $21,4 \%$ do sexo masculino. Esses acadêmicos são de diferentes cidades, como José de Freitas, Altos, Campo Maior, Demerval Lobão e União, a média distância da cidade onde os acadêmicos moram para o Centro de Saúde da Universidade era de 55,5 $\mathrm{Km}$. No que concerne às horas de sono, a média de sono dos alunos pendulares foi de 5,8 horas (DP: 1,4 horas), devido a grande distância que precisam percorrer diariamente, enquanto os alunos nãopendulares tiveram uma média de 6,7 horas (DP: 1,6 horas). Considerações Finais: Este estudo concluiu que uma grande parcela dos acadêmicos pendulares possuem distúrbio do sono e os Pesquisa e Extensão 
demais possuem uma má qualidade do sono e esse fator está intimamente relacionado à distância percorrida diariamente. Porém, os alunos não- pendulares também apresentaram qualidade ruim do sono..

Palavras-chave: Sono; Estudantes de Ciências da Saúde; Privação do Sono.

Área Temática: Ciências da Saúde.

E-mail do autor principal: geisasantana97@gmail.com

\section{INTRODUÇÃO}

O sono pode ser definido como suspensão normal e temporária do nível de consciência, faz parte do ciclo vigília - sono, e é regulado por um componente circadiano determinado pelo relógio biológico e por um processo homeostático que é caracterizado pela pressão do mesmo (CRABTREE; WILLIAMS, 2009). É um fenômeno vital, durante o qual se "desligam" ou atenuam-se mecanismos e sistemas orgânicos, com vistas à prevenção da exaustão, e são executados processos de recuperação e compensação de gastos energéticos e bioquímicos, ocorridos no período de atividade (SHUKLA; BASHEER, 2016).

Segundo Mello et al (2018), o sono é composto por duas fases importantes, a fase dos movimentos rápidos dos olhos (REM) e a fase sem movimentos rápidos dos olhos (NREM), representando distintos componentes neurais. Atualmente reconhece-se a importância da qualidade de sono, pois, segundo estudos, sabe-se que a má qualidade do sono afeta diretamente a qualidade de vida humana, pois parece estar envolvida com o aumento da morbidade por disfunção autonômica, distúrbios psiquiátricos, acidentes automobilísticos e de trabalho, envelhecimento precoce, depressão, insuficiência renal, intolerância à glicose, hipercortisolemia; e com a diminuição da eficiência laboral, etc (DANDA et al., 2005, QUINHONESMC; OMESM, 2011).

Os universitários devido a rotina de estudo, desafios do ensino superior, estão propensos a obter distúrbios do sono. Esta população que em sua maioria jovem, pode apresentar maior privação de sono com tendência a sonolência diurna excessiva, tem como consequência, problemas de memória, diminuição do rendimento acadêmico, irritabilidade, problemas comportamentais como estresse e ansiedade (MARTINI et al., 2012). Pois, o sono exerce influência nas funções endócrinas, termorregulação, conservação de energia, tem uma função 
biológica fundamental na consolidação da memória (RIBEIRO et al, 2014).

Segundo Silva et al. (2012), o movimento pendular é o deslocamento frequente temporário entre o município de residência e o município de trabalho ou estudo. Eles podem ocorrer de duas formas: individual ou em grupo de pessoas, por meio de transportes coletivos, privados ou públicos. Continuando, o autor cita que a denominação deriva do seu fenômeno característico, um movimento de vaivém semelhante à oscilação de um pêndulo.

Em decorrência da importância de se ter uma qualidade de vida e de sono, e da grande incidência de acadêmicos que estudam fora do seu domicílio no Piauí, do tempo gasto para esta locomoção diária, do cansaço, da grande carga de estudo e das atividades acadêmicas, surgiu o interesse de investigar qual o impacto do movimento pendular sobre o sono de acadêmicos de uma instituição de ensino superior.

Assim, esse trabalho teve como objetivo avaliar e comparar a qualidade do sono de universitários pendulares e não - pendulares dos cursos da área da saúde.

\section{MÉTODO}

Trata-se de uma pesquisa observacional, transversal, descritiva e comparativa. O estudo foi desenvolvido em uma Instituição de Ensino Superior do Piauí, a coleta de dados ocorreu no período de setembro de 2017, tendo como parecer de aprovação do CEP a numeração: $1.978 .334 / 2017$.

A amostra foi constituída por 14 estudantes pendulares e pelo mesmo número 14, de não-pendulares dos cursos de Psicologia, Fisioterapia, Enfermagem e Medicina, que estudavam em período integral. Não foram incluídos os alunos pendulares que moravam numa distância menor que $40 \mathrm{Km}$ da capital. Como também, aqueles que desistiram da pesquisa, ou não responderam os questionários de forma completa.

Primeiramente foram esclarecidos os objetivos do estudo e procedimentos a serem seguidos, posteriormente foi solicitada a assinatura do Termo de Consentimento Livre e Esclarecido. Foram aplicados o questionário de "Índice de Qualidade do Sono de Pittsburgh", que tem o objetivo de avaliar a qualidade de sono em relação ao último mês e uma ficha de informações dos participantes elaborada pelas pesquisadoras que avalia vários itens, como a distância percorrida, o meio de transporte e o tempo gasto diariamente.

A pesquisa teve como benefício o conhecimento da qualidade do sono desses alunos

E - book Tripé do Ensino Superior: Ensino, Pesquisa e Extensão 
para os pesquisadores e gestores das universidades e as orientações ao participante entregue por meio da cartilha ao final da coleta de dados.

Os dados foram inseridos em planilha EXCEL e realizados o tratamento estatístico por meio da análise dos dados pelo programa de estatística BioEstat 5.3. Foram apresentados em média e desvio padrão. Realizou-se correlação de Pearson, considerando forte o $\mathrm{r}>0,70$ e os dados foram comparados com Teste de Mann Whitney, considerando estatisticamente significante o $\mathrm{p} \leq 0,05$.

\section{RESULTADOS E DISCUSSÃO}

A população de estudo foi constituída por 28 universitários da área da saúde, destes 14 eram pendulares e 14 não pendulares, sendo 8 acadêmicos de Enfermagem, 6 de Fisioterapia, 2 de Medicina e 12 psicologia, compreendendo do $1^{\circ}$ ao $12^{\circ}$ período. Destes participantes $78,6 \%$ eram do sexo feminino e 21,4 \% do sexo masculino. Esses acadêmicos são de diferentes cidades, como José de Freitas, Altos, Campo Maior, Demerval Lobão e União. A tabela 01 apresenta a caracterização dos universitários pendulares e não pendulares, segundo a média de idade e sexo.

Tabela 1: Caracterização das amostras $(\mathrm{N}=28)$.

\begin{tabular}{lccc} 
& \multicolumn{1}{c}{ Idade } & $\begin{array}{c}\text { Média de distância } \\
\text { percorrida }\end{array}$ & Média de sono \\
& 22,4 anos \pm 5 anos & $55,5 \pm 16$ & $5,8 \pm 1,6$ \\
Pendulares & 19 anos $\pm 1,5$ anos & $7,5 \pm 3,5$ & $6,7 \pm 1,4$ \\
\hline
\end{tabular}

Fontes: Autores

A média de distância da cidade onde os acadêmicos moram para o Centro de Saúde da Universidade é 55,5 Km e com uma duração média de deslocamento diária de $2 \mathrm{~h}$ e 24 minutos e 92,8\% utilizam o transporte público e afirmam ser de péssima qualidade, estes afirmam ficar em média 32 minutos na parada a espera do transporte público. Já os alunos não - pendulares a maioria utiliza carro e a média de deslocamento é de $7,5 \mathrm{~km}$, com a duração média de 15 minutos. 
No que concerne às horas de sono, a média de sono dos alunos pendulares foi de 5,8 horas (DP: 1,4 horas), devido a grande distância que precisam percorrer diariamente para chegar a Universidade, uma média de $55,5 \mathrm{Km} \pm 16 \mathrm{Km}$, esse valor é inferior à média geral da população adulta brasileira (7-9 horas) e mundial (6,5-8,5 horas) (AKHLAGI, A, 2009). Enquanto os alunos não-pendulares tiveram uma média de 6,7 horas (DP: 1,6 horas).

Esses valores são inferiores ao recomendado pela National Sleep Foundation, que sugere que a média de sono de adultos jovens e adultos seja entre 7 a 9 horas, dessa forma, considerou-se duração insuficiente o sono de 24 horas inferior a 6 horas/dia para adultos de 18-64 anos, devido as inúmeras repercussões no corpo humano. Mas, foi similar aos resultados encontrados em outros estudos também desenvolvidos com universitários brasileiros da área da saúde, estes constataram que os acadêmicos dormem menos que 7 horas por dia (SENGER, ROCHA, MORSCH, 2019; ARAÚJO, LIMA, 2014).

No período avaliado $42,8 \%$ dos universitários pendulares apresentam uma latência de sono, menor que 15 minutos, o que significa uma privação grave do sono, enquanto os alunos não-pendulares 38,7\% apresentaram esse nível de privação. Em relação a qualidade subjetiva do sono dos alunos - pendulares, $(14,29 \%)$ relataram ter um sono muito ruim, $(28,57 \%)$ ruim, (50\%) bom e muito boa $(7,14 \%)$. Os acadêmicos não pendulares apresentaram $(35,7 \%)$ de sono ruim, $(42,8 \%)$ bom e $(21,5)$ muito bom, ao reaplicar o questionário $(7,1 \%)$ relataram ter um sono muito ruim, $(50 \%)$ ruim, $(35,7)$ bom e $(7,1 \%)$ muito bom.

Ao correlacionar a distância percorrida com as variáveis do Questionário de Pittsburgh, constatou-se que existe uma correlação fraca entre distância e a considerado dificuldade para iniciar o sono quando o indivíduo apresentar a percepção de levar mais de 30 minutos entre o preparo para dormir e adormecer (Tabela 2).

Tabela 2: Correlação entre as variáveis do Questionário de Pittsburgh e Distância Percorrida Diariamente (N=28).

Coeficiente de Spearman (rs)

Correlação entre a Eficiência Habitual do Sono

0.7003

x Distância Percorrida

Correlação entre a Sonolência Diurna x

0.1772

Distância Percorrida

Correlação entre Latência do Sono x Distância

0.0434

Percorrida

E - book Tripé do Ensino Superior: Ensino, Pesquisa e Extensão 
Correlação entre Sonolência x Distância

0.2958

Percorrida

Fonte: Autores

Neste estudo ao compara a Eficiência Habitual do Sono com a distância percorrida diariamente foi encontrada uma relação forte $(0,7)$, então, a distância percorrida diariamente afeta diretamente a qualidade de sono dos universitários pendulares. Em relação a sonolência diurna e sonolência pela Escala de Epworth a correlação foi fraca, porém, ao serem questionados se o fato de ser pendular atrapalha no rendimento acadêmico $(85,5 \%)$ afirmaram que sim, pois o deslocamento diário por ser demorado e de péssima qualidade causa fadiga, estresse, sobrecarga e diminui o tempo de algumas atividades da Universidade, principalmente por ser tempo integral. E a correlação entre a Latência do sono e Distância Percorrida é moderada $(0,4)$, pois, muitos adormecem menos de 5 minutos ao se deitarem.

Em relação ao entusiasmo para fazer as atividades habituais, $(21,4 \%)$ dos pendulares relataram ser um problema leve, $(50 \%)$ um problema razoável e $(28,6 \%)$ um grande problemaA qualidade do sono entre estudantes da área da saúde é um assunto que vem sendo investigado e explorado nos últimos anos, devido a suas repercussões silenciosas na rotina acadêmica e na vida pessoal dessa população. Assim, a investigação por meio de um instrumento validado para o português do Brasil e com possível quantificação, como o PSQI é de extrema importância para o acompanhamento da saúde do sono desses acadêmicos, auxiliando o planejamento de ações de conscientização dessa problemática, (BERTOLAZI, A. et al., 2011).

Ao fim desta análise dos 14 componentes pendulares do PSQI foi evidenciado que parcela substancial dos universitários investigados $(64,2 \%)$ possui qualidade ruim do sono (PSQI 5 a 10) e $(35,8 \%)$ possuem distúrbio do sono (PSQI >10). E dos 14 componentes não pendulares $(36,3 \%)$ possuem uma boa qualidade de sono, $(50 \%)$ possuem uma má qualidade de sono e $(13,7 \%)$ possuem distúrbio do sono.

A maioria dos alunos pendulares classificaram a qualidade do sono como ruim e os não pendulares como boa, esse dado é alarmante, pois, um dos pilares do padrão de sono humano é determinado justamente pela autoavaliação de satisfação com o sono. Portanto, é importante que o universitário tenha uma autopercepção eficiente acerca do seu sono (ARAÚJO et al., 2013). Ter uma boa qualidade do sono é essencial para a saúde física e saúde mental. Isso influencia a função imunológica, a restauração da energia cerebral, as funções linfáticas cerebrais (para eliminar o desperdício e facilitar a distribuição de vários compostos no cérebro), 
revertendo a degradação do desempenho induzido durante o despertar e também plasticidade neuronal (GOMES, 2020).

\section{CONSIDERAÇÕES FINAIS}

Este estudo concluiu que uma grande parcela dos acadêmicos pendulares possuem distúrbio do sono e os demais possuem uma má qualidade do sono e esse fator está intimamente relacionado à distância percorrida diariamente. Porém, os alunos não- pendulares também apresentaram um sono ruim, o que sugere que os acadêmicos da área da saúde e de tempo integral possuem uma redução do tempo e qualidade do sono. Nesse contexto, faz-se necessário ações de promoção da saúde para que o próprio acadêmico atue na construção da sua qualidade do sono.

\section{REFERÊNCIAS}

ARAÚJO et al. Avaliação da qualidade do sono de estudantes universitários de Fortaleza-CE. Texto contexto - enferm. [Online], v. 22, n. 2, p. 352-360, 2013.

CRABTREE, WILliAMS. Normal sleep in children and adolescents. Child Adolesc Psychiatr Clin N Am, v. 18, n. 4, p. $799-811,2009$.

DANDA et al. Padrão do ciclo sono-vigília e sonolência excessiva diurna em estudantes de medicina. J Bras Psiquiatr, v. 54, n. 2, p. 102 - 106, 2005.

GOMES MM, Unveiling sleep mysteries: functions. Rev Bras Neurol [Online], v. 56, n. 1, p.05$10,2020$.

MARTINI $\mathrm{M}$ et al. Fatores associados à qualidade do sono em estudantes de Fisioterapia. Fisioter Pesq. v. 19, n. 3, p. 261 - 267, 2012.

MELLO et al. Cronotipo e qualidade do sono de acadêmicos do primeiro ano do curso de medicina da cidade de Maringá-PR. Revista Saúde e Pesquisa, v. 11, n. 2, p. 287 - 292, 2018.

RIBEIRO et al. O impacto da qualidade do sono na formação médica. Revista da Sociedade Brasileira de Clínica Médica, v. 12, p. 8-14, 2014. 
SHUKLA, BASHEER. Metabolic signals in sleep regulation: recent insights. Nat Sci Sleep, v. 8, p. $9-20,2016$.

QUINHONES, GOMES M. Sono no envelhecimento normal e patológico: aspectos clínicos e fisiopatológicos. Rev Bras Neurol, v. 47, n. 1, p. 31 - 42, 2011 